\title{
Implementation of Protective Device for Lineman Protection in Real Time Operation
}

\author{
T.Arun Prasath, Suprabhat Bharti, B.Pavan Kumar, A.Harsha Vardhan
}

\begin{abstract}
: this paper is proposed to control an electrical switch with the assistance of OTP based password. A keypad is associated with the task to enter the secret password. During the electric line fixing Lethal electrical accidents to the lineman are increasing because of the lack of communication between the linemen working staff and the electric substation officers. This proposed framework gives an answer, which can guarantee the wellbeing of the lineman. Since the control to turn on/off lies with the lineman. So there is the arrangement in the system and a password is required to operate the electrical switch i.e. on and off. The lineman has to carry the RF-ID tag that will be inserted into $R F-I D$ reader to generate a one-time password. OTP will be received by the lineman. After inserting correct OTP Lineman will trip the supply and after securely repairing it, again he can turn the supply for respective phase. A microcontroller from ARDUINO family is used in the framework for complete operation and control. The microcontroller is interfaced with the matrix keypad to enter the secret one time password. The entered secret OTP is compared with the password stored in the microcontroller's Read-only memory. If OTP matches with the stored one than only electrical switches can be turned on or off otherwise it will say the wrong password. A light emitting diode is used to intimate the activation and deactivation of the electrical switch. Because of the use of EEPROM, the user does not have to remember the secret password. The microcontroller is interfaced with the Global system of mobile (GSM) to monitor the operation by lineman by the means of SMS. When lineman trip the supply a message will be sent to a higher authority about the Activation and deactivation of the electrical switch.
\end{abstract}

Keywords : Microcontroller, Diodes, $R F-I D$ reader, $R F-I D$ tag, Relays, Crystal, Matrix Keypad, Resistors, Capacitors, LED, LCD display, Transformer, Relay Driver IC, Voltage Regulator, GSM module

\section{INTRODUCTION}

An electrical circuit breaker is a naturally worked electrical switch intended to shield an electrical circuit from harm caused by abundance flow from an over-burden or short circuit. Its fundamental function is to interrupt the current stream after a fault is identified. In contrast to a fuse, which works once and after that it must be replaced, an electrical switch can be reset to continue the ordinary activity. That can

* Correspondence Author

T.Arun Prasath,* EEE, Kalasalingam Academy of Research and Education, India.Email: arun.aklu@gmail.com

Suprabhat Bharti, EEE, Kalasalingam Academy of Research and Education, India.Email: suprabhat193@gmail.com

B.Pavan Kumar,EEE, Kalasalingam Academy of Research and Education, India.Email: pavankumarburra178@gmail.com

A.Harsha Vardhan,EEE, Kalasalingam Academy of Research and Education, India.Email: harshav798@gmail.com
Revised Manuscript Received on December 15, 2019.

be done either physically or manually. To operate, keep up and fix the electrical power lines that supply power to the factories and homes is the major problem faced by the electrical lineman and the staff. This task is tiring, challenging and hazardous assignment. The electrical lines that transmit power supply to our homes and factories have a high voltage coursing through them. Indeed, even a little error can cause extreme causalities, high degree burns and deaths cause in most of the cases.

Thus, we realized that Security is the prime worry in our everyday life. Everybody should be secured much as reasonably possible. While repairing the electrical lines because of the absence of information and communication between the electrical substation staff and support staff (lineman) these days, electrical accidents to the lineman are increasing, this proposed system gives all solution and guarantee the safety of the lineman and staff. The control to trip on or off the line will be kept up by the lineman because this proposed system has the special arrangement in which a secret one time password is required to operate the electrical circuit breaker.

The proposed system is completely guarded by a microcontroller from the AVR family. The microcontroller is interfaced with matrix keypad that will be used to enter the secret OTP. The lineman has to enter the RF-ID reader into the RF-ID tag and OTP will be requested. The secret OTP sent is entered and compared with the password stored in the ROM of the microcontroller. If the entered secret password matches then the only lineman can trip the supply otherwise it will show the wrong password. Again it asks for the correct password. LCD will display all the information. The password will be sent on the registered mobile number of the lineman. After repairing they do not have to go substation to close the circuit. Lineman can do this after the repairing.

A piece of information will also be sent to the higher officials about the person and place where this repairing is going to take place. During the time of repairing no other individual can on the electrical switch. If any person is trying without permission than also a message will be sent to officers so that proper action can be taken also a buzzer will be connected so that person who is doing in an unauthorized way can be caught.

By doing some changes in the system it can be used for the various system like door locking system, fridge etc. And furthermore, it can be used to control electrical appliances to save energy. This can be utilized in lodgings and shopping centers like places to save energy. It can also be used in a genetic laboratory where very sensitive electricity is needed, and any other public area. 


\section{Implementation of Protective Device for Lineman Protection in Real Time Operation}

\section{LITERATURE SURVEYS}

Electric Line Man Safety using Micro Controller with GSM Module: This proposed system gives an answer that guarantees the wellbeing of support staff i.e. lineman. After detection of a fault in the electric line, the lineman sends SMS and then the supply line is turned off which can again be turned on after correction and repairing of fault but the main disadvantage is that lineman again has to go to the substation to switch on the power supply. It completely works on the microcontroller. Alert messages to the power circuit for lineman security: This proposed system is planned in such way that when support staff i.e. lineman goes to repair he makes a call to the circuit breaker using GSM, which is connected to the main supply then it automatically switch off the power supply of a particular line and whenever the lineman finish his work then again he has to switch on the power supply of that line by going to substation. No communication between higher officials and lineman. Electric lineman protection using user-changeable password based circuit breaker: The password is stored in the EEPROM of microcontroller and after tripping the supply using the password the password gets changed and again lineman has to remember the password. Here relay is used to on or off the circuit and keypad is used to enter the password. A lamp will show the wrong or wright password entered. It is not a programmed process so everything must be done physically. Password Based Circuit Breaker: An electrical circuit breaker is a naturally worked electrical switch intended to shield an electrical circuit from harm caused due to over-burden or short circuit. Its fundamental function is to recognize a fault condition and break the flow of current. When worked physically lethal electrical can occur to the lineman are increasing due to the electric line fixing because of the absence of information and coordination between the working staff and the substation electric staff. So as to maintain an intentional distance from such accidents, the breaker can be so structured to such an extent that just approved individual can work it with a secret key. But they have to remember the password.

\section{PROPOSED SYSTEM}

The world is growing fast. But in case of electric maintenance work when electric faults occur than the entire consumer's distribution lines are cut off. Due to this the places where faults do not occur they also have to face a problem. Mainly the industry faces a problem. So, there should be a system which automatically controlled and that can save workers from the accidents. The microcontroller from the AVR family is used along with a rectified power supply. GSM is interfaced with the microcontroller which is used to send the message to the lineman as well as higher officials. To enter the one-time password a matrix keyboard is interfaced with the Arduino microcontroller. Initially, the password is stored in the EEPROM of the microcontroller and it is matched with the one-time password received by the lineman on his mobile phone. If the entered password is correct than supply will be tripped otherwise it will show the wrong password and again it will ask for the correct password.

In case of fault maintenance work can be done by disconnecting the supply of that line only and another line will not be tripped off. For this Lineman has to carry RF-ID tag that will be inserted into RF-ID reader to generate a one-time password. OTP will be received by the lineman on his registered number. That password will open the supply so that they can work without any risk, after fixing the fault they can turn the supply on from there only. LED is used to show the tripping of supply i.e. on or off. A message will be sent to higher officials about the connection and disconnection of supply.

\section{METHODOLOGY}

The program is coded in embedded $\mathrm{C}$ language for the working of the electrical circuit breaker. A matrix keypad, EEPROM, voltage regulator, relay drive, RF-ID reader and LCD is interfaced with Arduino microcontroller.

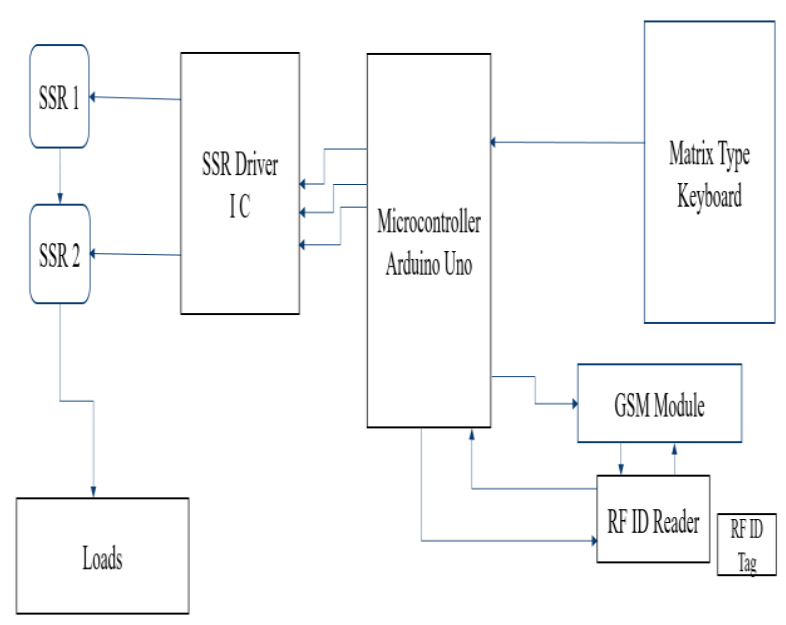

\section{FIG. 1: BLOCK DIAGRAM}

According to the circuit diagram connections are given and at the time of connection, there should not be the common connection between alternating current and direct current. A 5 volt regulated direct current power supply is given to the controller by the help of 5 volts alternating current supply. Since now there is supply in both DC and AC supplies so switch on the both DC and AC connection. Do not touch the relay because it has a 230 volt supply. LCD shows "enter password". Enter password against the symbol '*' in the LCD with the help of matrix keyboard. Thus entered password is correct so it will show circuit breaker is unlocked and LCD will show the changed condition of the circuit breaker. Suppose the password entered is wrong then it will display "access denied" and enter the correct password. Because of the OTP connection the respective person can request the password again by entering the RF-ID tag into it. After repairing that person can only turn it on by entering that OTP received by him. Here, numerous loads can be opened or closed at the same time. Therefore we have structured a system which isn't just easy to handle yet in addition more secure to utilize and environment-friendly as well. Numerous lives can be saved by basically utilizing a microcontroller.

Blue Eyes Intelligence Engineering 
The secret OTP guarantees that just the lineman can work the system and hence zero chance of another person to interfering the proposed system. So, logically lineman can work without stress because they will not have to travel more to open or close the circuit. Therefore, it is an exceptionally valuable, conservative and safe method for using circuit breakers.

\section{- Algorithm}

This is a step by step process. Here all the process to do the request of password lies with lineman only. After the repairing again lineman will request for secret one time password to close the circuit. In all these process information is also sent to higher officials. This is highly secure process. A buzzer is also connected with the system in case of wrong password pressed. Also if some other person will try to break the circuit than the LCD will show unauthorised. And the suspicious activities will also be intimated to the officials through SMS.

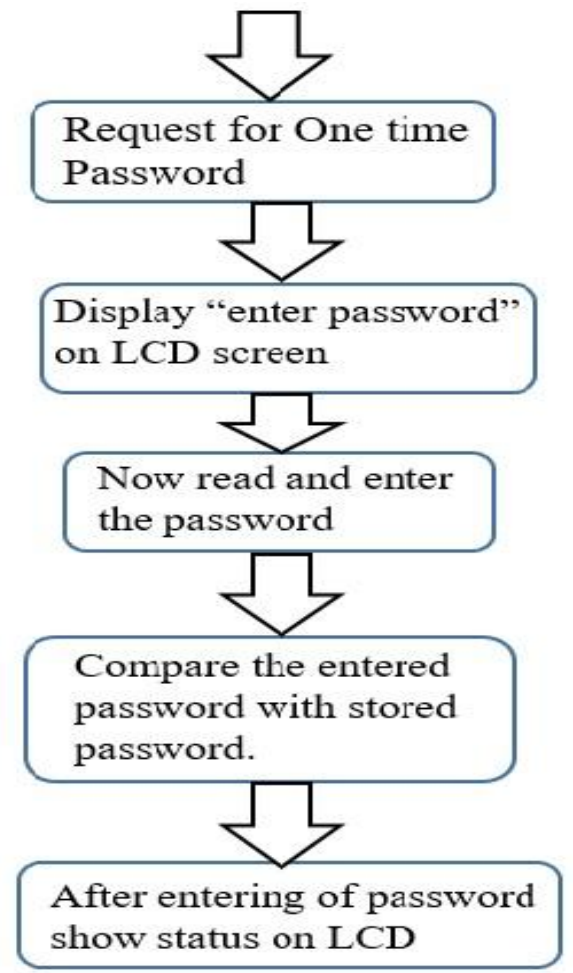

FIG. 2: ALGORITHM

\section{RESULT AND DISCUSSION}

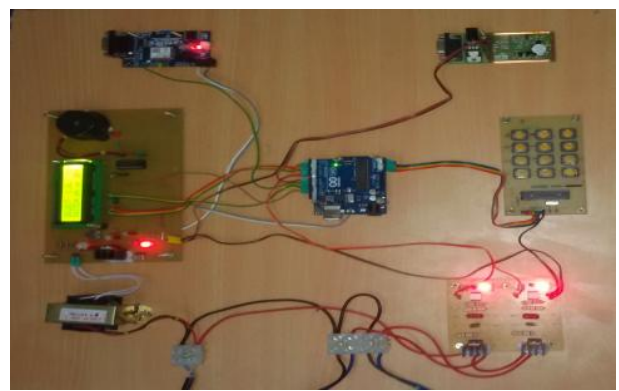

FIG. 3: HARDWARE CONNECTION

At first circuit breaker will be in locked condition. It will ask for one-time password received by the lineman when they enter RF ID tag into RF-ID reader. If the password matches with a stored password than the system will be opened else it will show the wrong password. The buzzer will give intimation about the wrong activities. The whole activities will be monitored by higher officials since all the information will be sent to them using GSM.

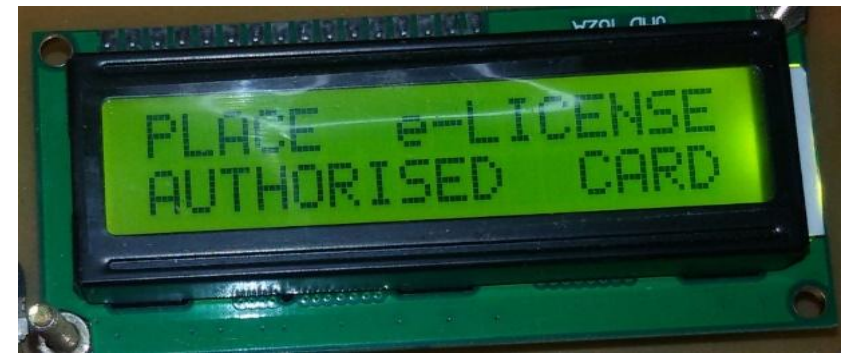

FIG. 4: FIRST OF ALL IT WILL ASK FOR AUTHENTICATION

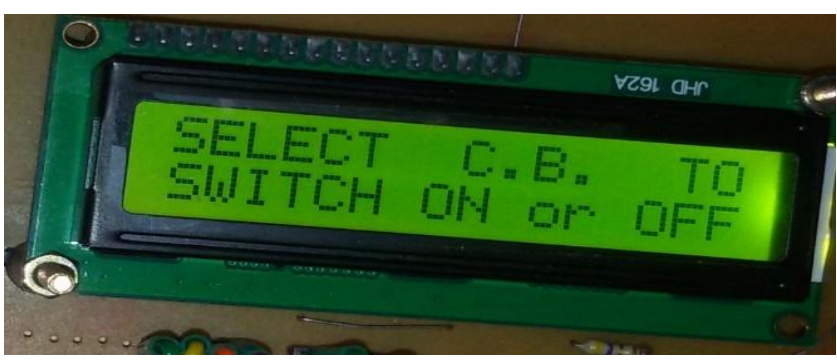

FIG. 5: IF THE CORRECT CARD IS GIVEN THAN IT WILL SHOW THE SELECT THE CIRCUIT BREAKER TO BE OFF

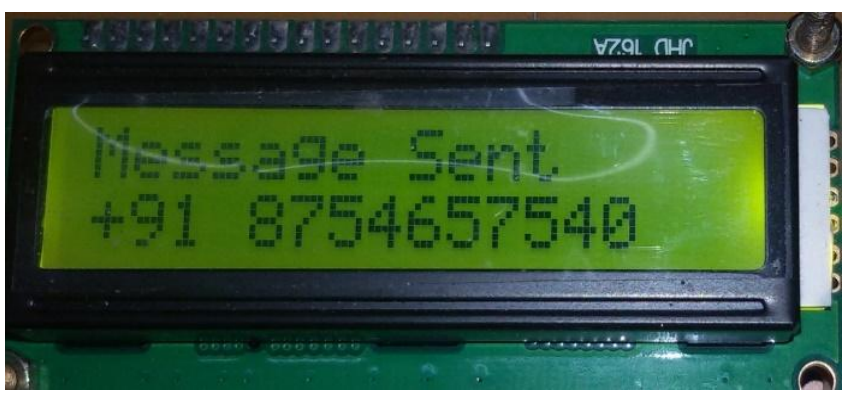

FIG. 6: AN OTP WILL BE SEND TO HIGHER OFFICIALS AND LINE MAN

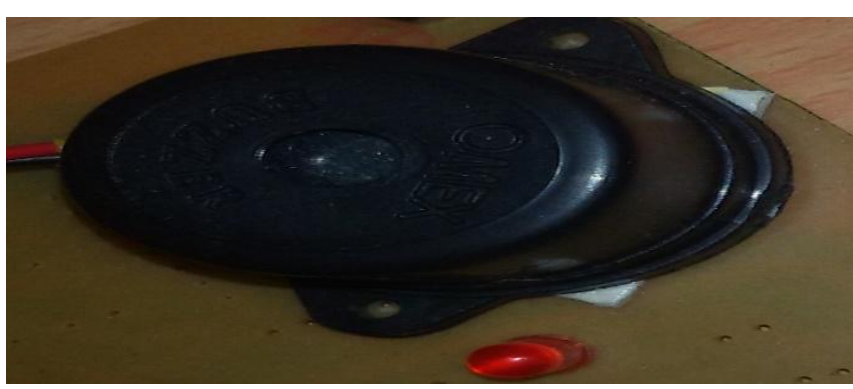

FIG. 7: IF PASSWORD WRONG

This proposed framework gives an answer, that guarantee the wellbeing of the lineman. Since lineman has the control to switch on and switch off the supply so no other person can change the supply during that time. This framework has a course of action with the end goal that a secret one time password is required to function the electrical circuit breaker. Therefore after successful repairing lineman can again close the circuit. 


\section{Implementation of Protective Device for Lineman Protection in Real Time Operation}

Because of one time-based password protection, there is no need to remembering and they can work safely. This will decrease the rate of accidents and protect the working staff. There is no need to open the supply for whole area in case of fault. Only defected area can be switched off and after successful repairing again it can be switched on. So this will decrease the frequent power cut of several area due to fault occurred at one place.

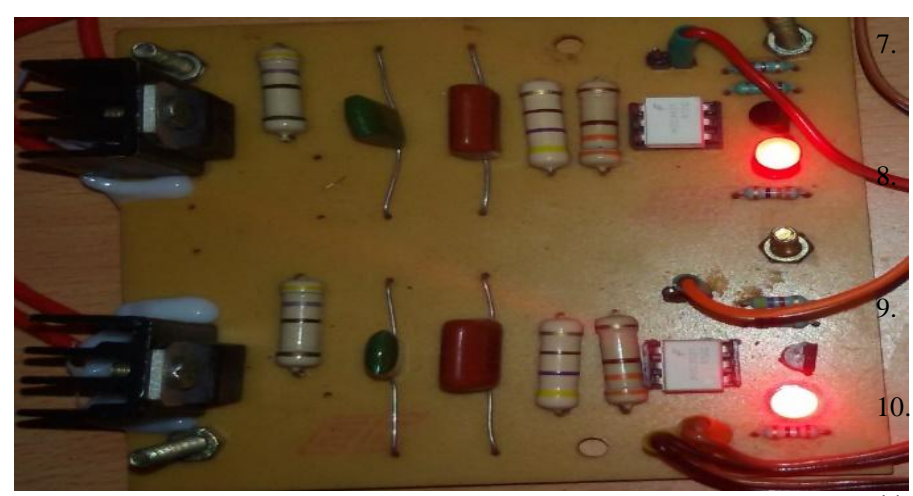

Fig. 8: Both loads are on

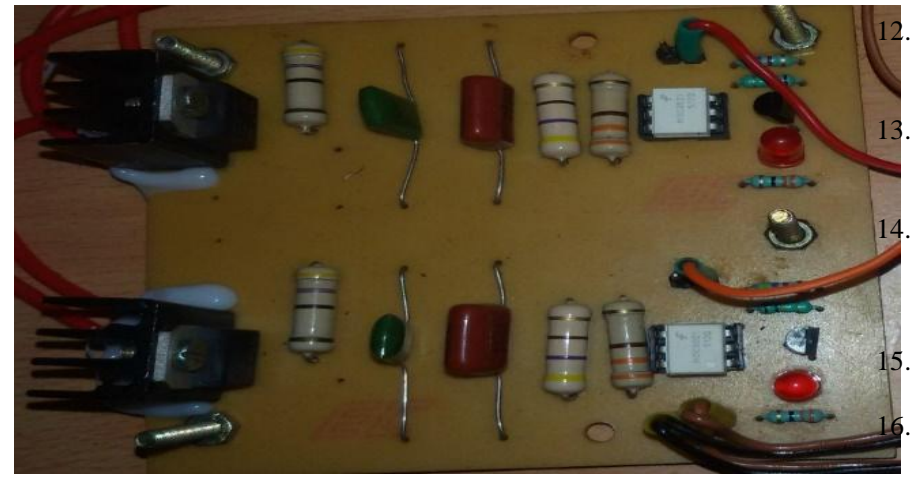

FIG. 9: AFTER PUTTING CORRECT OTP DESIRED CIRCUIT BREAKER WILL SWITCH OFF

VI CONCLUSION

Circuit breaker tripping can be done using one-time password generated. The password is random and the proposed system can be operated effectively and efficiently with the newly generated code. With the help of RF-ID reader and tag only authorized person can get OTP and random password. So, no one can steal the password and effectively provide safety to electric lineman and staff. It is economical and it can be easily installed. This system can also be implemented in many other public areas also. This proposed system has less cost and easy to install. This framework can likewise be executed in numerous other open zones too.

\section{REFERENCES}

1. Payman Dehghanian, Mladen Kezunovic, "Cost/benefit analysis for circuit breaker maintenance planning and scheduling", North American Power Symposium (NAPS) 2013, pp. 1-6, 2013.

2. Farzaneh Pourahmadi, Mahmud Fotuhi-Firuzabad, Payman Dehghanian, "Identification of critical components in power systems: A game theory application", Industry Applications Society Annual Meeting 2016 IEEE, pp. 1-6, 2016.

3. Masoud Asghari Gharakheili, Mahmud Fotuhi-Firuzabad, Payman Dehghanian, "A New Multiattribute Decision Making Support Tool for

Identifying Critical Components in Power Transmission Systems", Systems Journal IEEE, vol. 12, no. 1, pp. 316-327, 2018.

4. Mohammad Tasdighi, "Inductive FCL's impact on circuit breaker's interruption condition during short-line faults", North American Power Symposium (NAPS) 2013, pp. 1-5, 2013.

5. Po-Chen Chen, Vuk Malbasa, Mladen Kezunovic, "Sensitivity analysis of voltage sag based fault location algorithm", Power Systems Computation Conference (PSCC) 2014, pp. 1-7, 2014

6. Farzaneh Pourahmadi, Mahmud Fotuhi-Firuzabad, Payman Dehghanian, "Application of Game Theory in Reliability-Centered Maintenance of Electric Power Systems", Industry Applications IEEE Transactions on, vol. 53, no. 2, pp. 936-946, 2017.

Jing-Min Wang, Ming-Ta Yang, "Realization of circuit breaker condition-based maintenance using optimal contact wear equation by the modified NM-PSO algorithm", International Transactions on Electrical Energy Systems, vol. 26, pp. 627, 2016.

Hamed Sabouhi, Ali Abbaspour, Mahmud Fotuhi-Firuzabad, Payman Dehghanian, "Reliability modeling and availability analysis of combined cycle power plants", International Journal of Electrical Power \& Energy Systems, vol. 79, pp. 108, 2016.

B. K. Bose, P. M. Szczesny, and R. L. Steigerwald, "Microcomputer control of a residential photovolatic power conditioning system," IEEE Trans. Ind. Applicat., vol. IA-21, pp. 1182-1191, Sept. 1985.

B. H. Cho and P. Huynh, "Design and analysis of microprocessor controlled peak power tracking system," Proc. 27th IECEC, 1992, vol. 1, pp. 67-72.

11. Wasynczuk.O, "Dynamic behaviour of a class of photo voltaic power systems," IEEE Trans. Power App. Syst., vol. PAS-102, pp. 3031-3037, Sept. 1983.

M. Kezunovic, Z. Ren, G. Latisko, D. R. Sevcik, S. Lucey, W.E. Cook, E.A. Koch, "Automated Monitoring and Analysis of Circuit Breaker Operation", IEEE Transactions on Power Delivery.

G. Ramya and N.Balakumar, Effectual and Lossless Electrical Power Generation Methodology using Wind-Lens Technology, Asian Journal of Applied Science and Technology, Volume 1, Issue 1, Pages 12-17.

J.Jasmine Christina and V.Karthikeyan, Design of low power oscillator for medical ultrasonic sensors with CMUT implementation, Asian Journal of Applied Science and Technology, Volume 1, Issue 1, Pages 68-72.

Veena, "Electric line man safety system with OTP based circuit breaker", SR Engineering College, Volume:2, May 2015

Muhaad Ali Mazidi and Janice Gillisllispie Mazid, "The Microcontroller and embedded system", Person Education,2nd edition,Issue: 1999

\section{AUTHORS PROFILE}

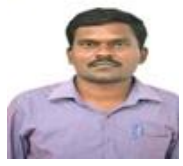

Dr.T.ARUNPRASATH is an Associate professor in Department Biomedical Engineering at Kalasalingam Academy of Research and Education.

Dr.T.ARUNPRASATH received his Ph.D. in Electronics and Communication Engineering from Kalasalingam University, Krishnankoil in 2015, his M.E. in Applied Electornics from Anna University in 2009 (Mohamed Sathak Engineering College) and his B.E. in Electrical and Electronics Engineering from Anna University (Syed Ammal Engineering College) in 2006. Dr.T.ARUNPRASATHresearch interests include biomedical instrumentation, image processing, image segmentation cloud computing, image segmentation. He has published 16 technical journals and 20 technical papers in refereed conferences in these areas.He is a life member of ISTE.

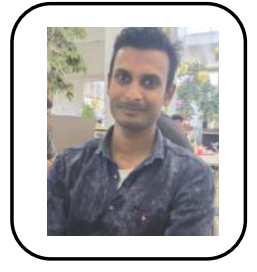

(CLAD)"
Suprabhat Bharti is a software engineer at HCL technology. He has completed a Bachelor of technology at Kalasalingam Academy of research and education from the electrical and electronics department with first-class Honours. He has published number papers in various publications. He has completed all the requirements and granted the title of "CERTIFIED LABVIEW ASSOCIATE DEVELOPER 
Pavan Kumar has graduated from Kalasalingam Academy of Research and Education with First Class Honours in Electrical and electronics engineering. He has done several courses and certifications like NPTEL course, PCB Design, Mobile Robotics, and Advanced Machining, Software Tools for Power System Studies, Industrial Internet of Things and its Deployments and Evolutionary Computation, Implementation of Machine Learning Algorithm Using MATLAB. He is also certified in NI LABVIEW and granted as the title of Associate Developer.

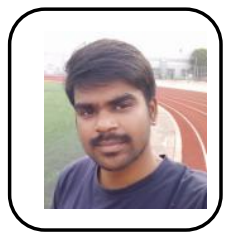

A.Harsha Vardhan has completed B. Tech in electrical and electronics engineering from Kalasalingam University. He has been gone through a project's digital information for the class that's helpful for the people who stay in village areas without having a proper internet connection. He has done several electronics and computer science engineering. 